\title{
DERECHO A LA INTEGRIDAD PERSONAL EN EL PERÚ. ASPECTOS CONSTITUTIVOS Y LIMITACIONES. EL CASO DE LAS PERSONAS PRIVADAS DE LIBERTAD
}

\begin{abstract}
RESUMEN: En el Perú el derecho a la integridad constituye un atributo que alcanza el ámbito físico, espiritual y síquico de la persona. Este derecho posee la máxima importancia ya que es el soporte indispensable del derecho a la vida, bastando el riesgo potencial de afectación para justificar la limitación de otros derechos. Ningún menoscabo en la integridad resulta admisible ya que nadie puede ser objeto de violencia moral, síquica o física, ni sometido a torturas y este derecho se encuentra tutelado tanto en el ámbito civil como en el penal a nivel local y por los tratados internacionales sobre derechos humanos. Las personas privadas de libertad tienen algunos derechos limitados pero la restricción no alcanza al derecho a la integridad pudiendo practicarse requisas que respeten este derecho así como la intimidad y realizar traslados siempre que las condiciones climáticas no afecten la salud del detenido.
\end{abstract}

Palabras clave: derechos humanos, derecho a la integridad, tortura, registros penitenciarios, traslado de detenidos.

\section{Omar SAR SUÁREZ*}

ABSTRACT: In Peru, the right to integrity encompasses a person's physical, spiritual and psychological aspects. This right is of the very highest importance as it is the indispensable foundation for the right to life and a potential risk of affecting it is sufficient to curtail other rights. No restriction on integrity is admissible as no one can be the object of moral, psychological or physical violence or tortured and this right is enshrined in both civil and criminal law at domestic level and also in international treaties on human rights. Prisoners have certain of their rights limited but there are no restrictions on the right to integrity; tours of inspection may be carried out but they must respect this right and the intimacy of the person, while prisoners may be transferred as long as the weather conditions do not affect their health.

Descriptors: human rights, right to integrity, torture, prison inspections, prisoner transfers.

* Catedrático de Derecho constitucional y Teoría del Estado en la Universidad de San Martín de Porres (Lima, Perú). Profesor asociado de la Academia de la Magistratura. Fecha de recepción: 11 de abril de 2007.

Fecha de dictamen: 12 de febrero de 2008. 
El respeto al contenido esencial del derecho a la integridad personal, tanto en lo que respecta al ámbito físico como en lo que atañe al ámbito espiritual y síquico de la persona, transita entre aquellos atributos que constituyen la esencia mínima imperturbable en la esfera subjetiva del individuo. Inclusive en aquellos casos en que pueda resultar justificable el uso de medidas de fuerza, éstas deben tener lugar en circunstancias verdaderamente excepcionales, y nunca en grado tal que conlleven el propósito de humillar al individuo o resquebrajar su resistencia física o moral, dado que esta afectación puede desembocar incluso en la negación de su condición de persona, supuesto inconcebible en un Estado constitucional de derecho. Asi lo ha establecido la Corte Interamericana de Derechos Humanos al establecer que "todo uso de la fuerza que no sea estrictamente necesario por el propio comportamiento de la persona detenida constituye un atentado contra la dignidad humana (Caso Loayza Tamayo, párrafo 57).

Sentencia del Tribunal Constitucional del Perú en el expediente 010-2002-AI/TC, Fundamento Jurídico 103.

\section{EL DERECHO A LA INTEGRIDAD}

La más caracterizada doctrina constitucional de nuestro país sostiene que el derecho a la integridad se refiere a la intangibilidad de los diversos elementos que componen la dimensión física de la persona humana.

Dentro de este concepto, la norma constitucional peruana en el inciso primero del artículo 2o. comprende, además del anterior, el derecho a la integridad síquica y moral. El derecho a la integridad síquica se refiere a la preservación de todas las capacidades de la psiquis humana, que incluyen las habilidades motrices, emocionales e intelectuales sin que ninguna 
de ellas pueda resultar afectada por la aplicación de métodos técnicos o sicológicos. El segundo

tiene un sentido restringido muy importante que es la dimensión ética de la persona. Como derecho quiere decir que cada ser humano puede desarrollar su vida de acuerdo al orden de valores que conforman sus convicciones, desde luego todo ello dentro del respeto a la moral y al orden público. ${ }^{1}$

Por otra parte se ha definido este derecho como "aquella facultad de rechazar cualesquiera agresiones corporales, estableciendo un deber general de respeto que alcanza validez erga omnes en el sentido de marcar una abstención común de cuantas actividades pudieran devenir perjudiciales al organismo humano". ${ }^{2}$

La efectiva protección del derecho a la vida exige el reconocimiento previo del derecho a la integridad ya que en múltiples ocasiones la afectación del primero y fundamental se inicia con el ataque al segundo.

Sostiene Quispe Correa que el derecho a la vida es, básicamente, la posibilidad real para desenvolverse a plenitud, no es la vida del esclavo, no es la vida miserable, sino que es, aunque resulte un pleonasmo, el derecho a vivir. ${ }^{3}$

Cabe destacar que en la perspectiva de este autor se produce una extensión del derecho a la identidad ya que toda persona goza de un conjunto de cualidades que las distinguen de otra y que deben ser respetadas. El nombre, el sexo, su cultura, son, entre otros, rasgos distintivos de una personalidad determinada y nadie puede usarla sin su autorización ni denigrarla impunemente. La plenitud moral, síquica y física, que componen la integridad del sujeto, son partes integrantes de esa identidad.

La consideración como bien de la personalidad, que se reconoce al cuerpo y a la integridad corporal, resulta del valor mismo reconocido a la vida y todo aquello que produzca su menoscabo o deterioro, bien por una afección, sustracción, disminución o alteración del soma humano, implica un ataque a este derecho.

1 Bernales Ballesteros, Enrique y Otárola Peñaranda, Alberto, La Constitución de 1993. Análisis comparado, Lima, Ed. Konrad Adenauer, Ciedla, 1996, p. 88.

2 Martínez-Calcerrada, Luis, Derecho médico, Madrid, Tecnos, 1986, vol. I, p. 442.

3 Quispe Correa, Alfredo, Los derechos humanos, Lima, Gráfica Horizonte, 2002, p. 109. 
El reconocimiento de la integridad y la vida entre los derechos fundamentales así como el derecho a la libertad han sido una constante en la jurisprudencia de nuestro máximo tribunal. En este sentido se ha resuelto que "a través de distintos fallos o sentencias constitucionales se ha establecido en forma uniforme la primacía y/o vigencia plena del derecho constitucional a la libertad individual e integridad física, las mismas que indudablemente son derechos fundamentales inherentes a la persona humana". 4

El derecho a la integridad física, de consiguiente, en cuanto a su verdadero alcance, si bien se proyecta sobre la realidad somática de la persona, también debe encuadrar a aquellas de sus facultades anímicas que, biológicamente enraizadas en su mismo ser, son parte indisociable del individuo - compuesto, no se olvide, de corporeidad y espiritualidad o mundo de la inteligencia-, de tal suerte que ambas, a la vez, deben constituir su exacto contenido, y, por ende, estar protegidas de cualquier ataque o intromisión de cualquier agente.

Como quedara expuesto, la tutela alcanza tanto la salud física como la salud síquica, por lo que consideramos mejor hablar de "derecho a la integridad corporal" que de "derecho a la integridad física", sobre todo si partimos de que aquella integridad corpórea recoge las dos realidades, la del cuerpo humano y la del espíritu.

Admitido lo anterior queda claro que resulta reprobable cualquier acto que produzca perturbación mental o trauma, porque el daño a la salud síquica ha de ser considerado indemnizable, tanto o más que el inferido a la salud física.

Nuestro Tribunal Constitucional tiene resuelto que

el contenido esencial del derecho a la integridad personal, en su dimensión física, sólo tolera que se genere una disminución permanente e irreversible de una función de un órgano del cuerpo humano, si con ello se busca evitar un riesgo inminente y grave para ese valor superior y primario, que es la vida humana. ${ }^{5}$

4 Considerando 2 de la sentencia del Tribunal Constitucional recaída en el expediente 1169-2000-HC/TC del 15 de diciembre del 2000.

5 Considerando 8 de la sentencia del Tribunal Constitucional recaída en el expediente 014-96-AI/TC del 28 de abril de 1997. 
De lo expuesto por el supremo intérprete de nuestra Constitución se deduce que concibe - como lo hiciéramos supra - una doble vertiente para este derecho a la integridad (física y sicológica). Adicionalmente deja establecido que sólo en caso de que se encuentre en riesgo la vida puede tolerarse una disminución física permanente e irreversible, como la que representa la esterilización quirúrgica ${ }^{6}$ (ligadura de trompas) en las mujeres.

En la misma sentencia se establece además que aun cuando

la Ley 26530, prima facie, permita (al no encontrarse prohibida) ${ }^{7}$ utilizar la esterilización como método de control de la natalidad, debería llevar a este Colegiado a evaluar si aquella permisión tácita se compadece o no con el derecho a la integridad corporal, que el inciso 1o. del artículo 2o. de la Constitución reconoce como derecho fundamental de toda persona.

La respuesta negativa se impone naturalmente. Más adelante estudiaremos la particularidad del caso en el que la esterilización tenga carácter voluntario, circunstancia que ha generado polémica y disparidad de opinión tanto en la doctrina nacional como internacional.

\section{NIVEL JERÁRQUICO DEL DERECHO A LA INTEGRIDAD PERSONAL EN LA DOCTRINA DEL TRIBUNAL CONSTITUCIONAL}

Consecuente con sus postulados teóricos y estableciendo comparación con otros derechos, el mismo Tribunal tiene resuelto que

El hecho de que exista una necesidad por mejorar los servicios de abastecimiento eléctrico en beneficio de un grupo de ciudadanos, no significa que ésta se satisfaga afectando los intereses de esos mismos ciudadanos o de otros distintos, como parece ocurrir en el presente caso con la instalación de una

6 El Tribunal Constitucional en la sentencia citada señala que "la esterilización está considerada por la más autorizada doctrina jurídica como una lesión a la integridad física, pues supone una intervención quirúrgica que elimina una función primordial del ser humano, como es la de procrear..."; agregando que "provoca incapacidad fisiológica permanente, y, en muchos casos, irreversible, lo que no concuerda con la naturaleza temporal de los métodos anticonceptivos...".

7 Este recurso a la ausencia de prohibición es el que permite un enorme margen para la arbitrariedad en diversos países particularmente aquejados por la superpoblación como China e India, por ejemplo. 
subestación aérea que constituye un riesgo potencial y, además, permanente para su propiedad y, sobre todo, para la tranquilidad, la integridad o la vida de quienes son moradores o habitantes de su predio. ${ }^{8}$

Nótese que en este caso el progreso o la libertad de contratación entre otros pueden ser limitados no sólo cuando afecten el derecho a la integridad, sino que basta con que exista un riesgo potencial para que opere la limitación.

En el mismo sentido se ha resuelto que la autoridad administrativa (en el caso la municipalidad metropolitana de Lima) puede revocar autorizaciones concedidas a empresas de transporte cuando "los pasajeros sean sometidos al peligro de accidentes $u$ otros hechos que atenten contra la seguridad e integridad física". 9

Se aprecia claramente en este caso la prioridad que asigna el máximo intérprete de la Constitución al derecho a la integridad con relación a los derechos de ejercer toda industria lícita y de asociación bastando una vez más la existencia de la puesta en peligro sin que se requiera la existencia objetiva del resultado lesivo.

En el mismo sentido se manifiesta el entonces fiscal de Lima, Hugo Denegri al sostener que

La conciencia de la excelsa dignidad de la persona humana, de su superioridad sobre las cosas y de sus derechos y deberes universales e inviolables, están fuera de toda discusión... Cuando se niegan las medicinas necesarias para atender la salud del anciano, de la mujer, del niño y en general de los enfermos, se viola la integridad de la persona humana al igual que las torturas morales o físicas, no sólo se ofende a la dignidad humana, sino que degrada la civilización humana, deshonran más a sus autores que a sus víctimas... Todos los habitantes de la nación tienen el derecho de ejercer toda industria y el de comerciar con la condición de que no sea perjudicial a la salud. ${ }^{10}$

En la doctrina de nuestro Tribunal Constitucional se ha dejado establecido también que el derecho personal a la integridad física, síquica y moral entre otros (como el derecho al honor, a la dignidad personal y a la

8 Considerando 2 literal g de la sentencia del Tribunal Constitucional recaída en el expediente 1006-2002-AA/TC del 28 de enero de 2003.

9 Considerando 1 de la Sentencia del Tribunal Constitucional recaída en el expediente 614-2000-AA/TC del 20 de septiembre de 2000.

10 Dictamen recaído en el expediente 347-90 del 31 de agosto de 1990. 
buena reputación, el derecho a una vida tranquila y en paz y el derecho a la igualdad entre los seres humanos) son valores más altos, constitucionalmente hablando, que la finalidad legítima de preservar el vínculo matrimonial.

Es decir, que ante la hipótesis de una colisión entre la protección de la familia (y por extensión la del matrimonio) y el derecho a la integridad debe preferirse este último en virtud de que goza de un rango superior.

Como consecuencia de lo anteriormente expuesto, el máximo intérprete de la Constitución ha resuelto que

si bien la finalidad de la conservación del matrimonio que contiene el artículo 337o. del Código Civil es legítima, no debe preferirse ni sacrificarse a la consecución de ésta, otras finalidades también legítimas y constitucionales, referidas a la defensa y desarrollo de la persona humana como tal, pues, a juicio de este Tribunal, los derechos humanos citados tienen mayor contenido valorativo y constituyen finalidades más altas y primordiales que la conservación del matrimonio. ${ }^{11}$

En el mismo sentido el Tribunal Constitucional tiene resuelto que toda vez que el incumplimiento en el deber de pagar la pensión alimentaria puede comprometer la integridad del beneficiario es perfectamente constitucional que se pueda aplicar una sanción privativa de libertad en caso de incumplimiento delictivo. Al respecto se ha resuelto que

cuando el literal "c", del inciso 24), del artículo 2o. de la Constitución prohíbe la prisión por deudas, con ello se garantiza que las personas no sufran restricción de su libertad locomotora por el incumplimiento de obligaciones cuyo origen se encuentra en relaciones de orden civil. La única excepción a dicha regla se da como el propio dispositivo constitucional señala, en el caso del incumplimiento de deberes alimentarios, toda vez que están de por medio los derechos a la vida, salud y a la integridad del alimentista, en cuyo caso el juez competente puede ordenar la restricción de la libertad individual del obligado. $^{12}$

11 Considerando 2 de la sentencia del Tribunal Constitucional recaída en el expediente 018-96-I/TC del 29 de abril de 1997.

12 Considerando 2 de la sentencia del Tribunal Constitucional recaída en el expediente 1428-2002-HC/TC. 


\section{LA INTEGRIDAD PERSONAL EN EL ÁMBITO DEL DERECHO PENAL}

Como ya se señalara dentro de la integridad corporal, han de encuadrarse aquellas cualidades de la persona que le son propias por su misma naturaleza racional y que, si bien no encajan en el ámbito puramente físico, son atributos predicables del ser humano que, como tal, goza de una inteligencia, carácter y temperamento que se proyectan al exterior, en un equilibrio de normalidad.

Los seres humanos gozan por naturaleza de un conjunto de libertades básicas que son inherentes a su personalidad; esas libertades básicas requieren garantías para asegurar su disfrute y no verse restringidas o violadas.

Las garantías son el marco que asegura el libre goce y ejercicio de las libertades fundamentales y están especialmente diseñadas contra los agentes del Estado, ya que sólo éste puede incurrir en violaciones a los derechos humanos. ${ }^{13}$ Los particulares podrán cometer delitos, los más graves de los cuales pueden ser calificados como de lesa humanidad, pero en todo caso serán sancionados por la normativa penal nacional (o excepcionalmente internacional) sin que resulten de aplicación las normas de protección de los derechos humanos.

La Constitución trata de cubrir todas las posibilidades de violencia contra una persona, porque no sólo repudia la posibilidad de que lo golpeen o le causen daño (conducta además tipificada como delito en los artículos 121, 121-A, 122, 122-A, 123, 124, 441 y 442 del Código Penal), sino también que se apele a otros medios (como el de las drogas) o se le fuerce con constantes amenazas.

El artículo 5o. de la Convención Americana de Derechos Humanos, en concordancia con la también vigente Convención contra la Tortura y otros Tratos o Penas Crueles, Inhumanos o Degradantes, han regulado en forma prohibitiva la afectación directa o indirecta de la integridad física o sicológica de la persona. Ello implica entre otras cosas la prohibición de las mutilaciones o reducción de la capacidad orgánica de una persona,

13 A pesar de lo expuesto corresponde anotar que en el ordenamiento peruano el habeas corpus procede contra actos de autoridad, funcionario o persona, es decir que se encuentra reconocida la posibilidad de la afectación por particulares abriendo la vía del proceso constitucional. 
las lesiones, la esterilización, la experimentación humana, la tortura y los tratos inhumanos, crueles y degradantes.

De más estará decir que lo dicho vale para todas las personas incluidas aquellas que se encuentran privadas de libertad, pues como veremos más adelante tal situación implica, objetivamente, la restricción de determinados derechos, pero en ningún caso puede afectarse la vida, la dignidad o la integridad de las personas.

Al respecto, el Tribunal Constitucional ha resuelto que:

analizados los autos, a tenor de los documentos médicos que obran a fojas veintiséis, treinticinco y cuarentisiete [sic]del expediente, se colige que el demandante Jesús Vladimir Osorio Anaya fue víctima de maltratos físicos con posterioridad a su detención policial, hecho que constituye una trasgresión al derecho constitucional contenido en el artículo 2o., inciso 24), literal "h" de la Constitución Política del Estado. ${ }^{14}$

Por lo tanto ningún menoscabo en el derecho a la integridad es admisible y cualquier actividad de los funcionarios públicos debe respetarlo escrupulosamente y esto resulta aplicable a las personas internadas en instituciones penitenciarias pero también a las que se encuentran a disposición de la autoridad policial por encontrarse sometidos a proceso de investigación.

El conjunto de libertades básicas y sus garantías constituyen los derechos de autonomía o de personalidad que se corresponden con los derechos civiles como los derechos a la vida, a la integridad física, a la libertad, a la seguridad, al libre tránsito, etcétera.

Frente a tales derechos existen otros derechos calificados como sociales y que son un conjunto de normas que obligan al Estado a prestar una serie de medios o servicios públicos dirigidos a las personas que no tienen satisfechas sus necesidades básicas.

La diferencia entre unos y otros aparece si se toma en cuenta que en los primeros lo que se exige es que el estado se abstenga de interferir mientras que en los segundos se le impone una actividad positiva en pro de la comunidad y en particular de aquellos sectores que están en situación de desventaja.

14 Considerando 2 literal "g" de la sentencia del Tribunal Constitucional recaída en el expediente 357-96-HC/TC del 13 de mayo del 1998. En el mismo sentido puede verse la sentencia recaída en el expediente 1073-97-HC-TC. 
En relación con las garantías constitucionales, el supremo intérprete de la Constitución ha dejado establecida, en el expediente 590-2001HC/TC (habeas corpus interpuesto por Abimael Guzmán entre otras), ${ }^{15}$ la procedencia del denominado habeas corpus correctivo que procede ante actos $\mathrm{u}$ omisiones que importen violación o amenaza de los derechos directamente conexos con el de la libertad, así como respecto de derechos diferentes a ésta, pero cuya eventual lesión se genera, precisamente, como consecuencia directa de una situación de privación o restricción del derecho a la libertad individual. ${ }^{16}$

La existencia del derecho a la integridad presupone que nadie puede ser objeto de violencia moral, síquica o física, ni sometido a torturas. Al respecto el inciso 1o. del artículo 2o. de la Constitución Política del Perú dispone que "Toda persona tiene derecho: 1. A la vida, a su identidad, a su integridad moral, síquica y física y a su libre desarrollo y bienestar". El literal "h" del inciso 24 del mismo artículo agrega que:

Nadie debe ser víctima de violencia moral, síquica o física, ni sometido a tortura o a tratos inhumanos o humillantes. Cualquiera puede pedir de inmediato el examen médico de la persona agraviada o de aquella imposibilitada de recurrir por sí misma a la autoridad. Carecen de valor las declaraciones obtenidas por la violencia. Quien la emplea incurre en responsabilidad.

\section{El Tribunal Constitucional peruano tiene resuelto que:}

La calificación de una pena como inhumana o degradante y, por lo tanto, como atentatoria del derecho a la integridad personal, depende, en buena cuenta, del modo de ejecución de la misma. No puede desatenderse que, aunque proporcional, la simple imposición de la condena ya implica un grado importante de sufrimiento en el delincuente, por ello sería inconcebible que ésta venga aparejada, a su vez, de tratos crueles e inhumanos que provoquen la humillación y envilecimiento en la persona. Dicho trato inhumano bien puede traducirse en una duración injustificada de aislamiento e incomunicación del delincuente. Siendo el ser humano un ser social por naturaleza, la privación excesiva en el tiempo de la posibilidad de relacionarse con sus pares genera una afectación inconmensurable en la siquis del individuo, con la

15 Considerando 1 de la sentencia 695-2002-HC/TC, considerandos 1 y 3 de la sentencia 055-2000-HC-TC, por ejemplo.

16 Considerando 1 de la sentencia del Tribunal Constitucional recaída en el expediente 1429-2002-HC/TC del 19 de noviembre de 2002. 
perturbación moral que ello conlleva. Dicha medida no puede tener otro fin más que la humillación y el rompimiento de la resistencia física y moral del condenado, propósito, a todas luces, inconstitucional. ${ }^{17}$

Con un criterio semejante, la doctrina española ha desarrollado la teoría de que el derecho a la integridad personal viene garantizado en el artículo 15 de la Constitución Española ${ }^{18}$ por la prohibición de tortura y otros tratos o penas inhumanos o degradantes.

Al respecto se ha sostenido que:

De la redacción del precepto constitucional se infiere que el constituyente entendió que tanto en el caso de la tortura como en el de los tratos inhumanos o degradantes, es innegable que se está ante figuras conocidas por el ordenamiento jurídico, contrarias a la integridad moral y, aunque muy cercanas a la tortura, distintas cuantitativa y cualitativamente de ésta. La necesidad, por tanto, de distinguir entre tortura y tratos inhumanos o degradantes ha llevado a que por vía jurisdiccional, concretamente por el Tribunal Europeo de Derechos Humanos, se haya proporcionado un concepto de los mismos. ${ }^{19}$

Dicho Tribunal ha definido los tratos inhumanos como "un trato que causa vivos sufrimientos físicos o mentales", ${ }^{20}$ y los degradantes como aquellos en los que se "humilla groseramente ante otras personas o se fuerza a actuar a la víctima en contra de su voluntad o conciencia". ${ }^{21}$

De lo expuesto podemos concluir que la tortura difiere de los tratos inhumanos y/o degradantes cualitativamente (por la finalidad propia de la tortura y la distinta función que en una y otros desempeña la condición del sujeto activo) pero también cuantitativamente (por la mayor o menor

17 Considerandos 104 y 105 de la sentencia recaída en el expediente 010-2002-AI/ TC del 3 de enero de 2003.

18 El artículo 15, correspondiente al título I, capítulo segundo, sección 1a., "De los derechos fundamentales y de las libertades públicas", establece que "Todos tienen derecho a la vida y a la integridad física y moral, sin que, en ningún caso, puedan ser sometidos a tortura ni a penas o tratos inhumanos o degradantes. Queda abolida la pena de muerte, salvo lo que puedan disponer las leyes penales militares para tiempos de guerra".

19 Rodríguez Mesa, María José, Torturas y otros delitos contra la integridad moral cometidos por funcionarios públicos, Granada, Comares, 2000, p. 352.

20 Sentencia del Tribunal Europeo de Derechos Humanos relativa al caso "Markx contra Bélgica" del 13 de junio de 1979.

21 Sentencia del Tribunal Europeo de Derechos Humanos relativa al caso "Campbell y Cosans contra el Reino Unido" del 25 de febrero de 1982. 
gravedad del sufrimiento infligido). La tortura en el orden internacional exige por tanto la concurrencia de un sujeto cualificado, una determinada finalidad y una especial intensidad en el ataque.

En el mismo sentido se ha sostenido que:

Tortura y tratos inhumanos o degradantes son, en su significado jurídico, nociones graduadas de una misma escala que, en todos sus tramos, denotan la causación, sean cuales fueren los fines, de padecimientos físicos o síquicos ilícitos e infligidos de modo vejatorio para quien los sufre y con esa propia intención de vejar y doblegar la voluntad del sujeto. ${ }^{22}$

La Convención Interamericana para Prevenir y Sancionar la Tortura, aprobada por la Asamblea General de la OEA el 9 de diciembre de 1985 define la tortura como

todo acto realizado intencionalmente por el cual se inflija a una persona penas o sufrimientos físicos o mentales, con fines de investigación criminal, como medio intimidatorio, como castigo personal, como medida preventiva, como pena, o con cualquier otro fin. Se entenderá también como tortura la aplicación sobre una persona de método tendientes a anular la personalidad de la víctima o a disminuir su capacidad física y mental, aunque no causen dolor físico o angustia física.

El artículo 175 del Código Penal Español23 está redactado en términos prácticamente idénticos a los del artículo 16 de la Convención de Naciones Unidas contra la Tortura. ${ }^{24}$ En ambos casos la conducta objeto de

22 Tal es la doctrina que emana de las sentencias 120-90 del 27 de junio de 1990 y 137-90 del 19 de julio de 1990 del Tribunal Constitucional español.

23 El artículo 175 dispone que "La autoridad o funcionario público que, abusando de su cargo y fuera de los casos comprendidos en el anterior, atentare contra la integridad moral de una persona será castigado con la pena de prisión de dos a cuatro años si el atentado fuera grave, y de prisión de seis meses a dos años si no lo es. Se impondrá, en todo caso, al autor, además de las penas señaladas, la de inhabilitación especial para empleo o cargo público de dos a cuatro años".

24 El artículo 16 de la Convención preceptúa que "1. Todo Estado parte se comprometerá a prohibir en cualquier territorio bajo su jurisdicción otros actos que constituyan tratos o penas crueles, inhumanos o degradantes y que no lleguen a ser tortura tal como se define en el artículo 1, cuando esos actos sean cometidos por un funcionario público u otra persona que actúe en el ejercicio de funciones oficiales, o por instigación o con el consentimiento o la aquiescencia de tal funcionario o persona...". 
prohibición viene delimitada negativamente con relación a los actos constitutivos de tortura por lo que se deduce que en el citado artículo el legislador ha tipificado esos tratos inhumanos o degradantes cometidos por funcionarios públicos.

De lo expuesto es evidente que se trata de un derecho primario y principal frente a algunos otros considerados secundarios como la salud que, tanto en su dimensión física como síquica, es incluido en la órbita de este derecho ad integrum. ${ }^{25}$ En el mismo sentido se ha sostenido que este derecho a la integridad física y mental, no es sino el derecho a la salud visto desde la perspectiva individual. ${ }^{26}$

\section{LA INTEGRIDAD PERSONAL EN EL CÓDIGO CIVIL}

El artículo 5o. del Código Civil establece que "El derecho a la vida, a la integridad física, a la libertad, al honor y demás inherentes a la persona humana son irrenunciables y no pueden ser objeto de cesión. Su ejercicio no puede sufrir limitación voluntaria, salvo lo dispuesto en el artículo 6o.".

Cabría preguntarse si, en el contexto que nos encontramos, una persona puede disponer libremente de su integridad física y el artículo 6o. del Código Civil establece que la prohibición es la regla general.

En la doctrina se ha sostenido que:

Por su naturaleza especial, no se trata de un derecho en cuanto facultad de su titular sobre un objeto. No se puede tener derecho sobre la propia persona, sobre el propio cuerpo, lo que se tiene es libertad para disponer de sí mismo. El derecho no se ejerce sobre la integridad física, sino que se tiene derecho a esa integridad, derecho a vivir, al honor, etcétera. ${ }^{27}$

25 Martinez-Calcerrada, Luis, op. cit., nota 2, p. 445. Corresponde anotar que disentimos en cuanto se señala que algunos derechos tendrían una prefered position, generando derechos de primera y derechos de segunda, una fundada crítica puede verse en Serna, Pedro y Toller, Fernando, La interpretación constitucional de los derechos fundamentales, Buenos Aires, La Ley, 2000, pp. 75 y ss.

26 Vallenas Gaona, Jesús R., Los derechos constitucionales en la Constitución peruana de 1993 (I) Los derechos de la persona en su dimensión vital, en http://www.uv.es/ ripj/4vaga.htm, al 3 de noviembre de 2003.

27 Hurtado, León, "El transplante de órganos humanos ante el derecho civil", Revista de Ciencias Penales, Santiago de Chile, t. XXVII, núm. 3, 1968, p. 232. 
La norma señalada establece que:

Los actos de disposición del propio cuerpo están prohibidos cuando ocasionen una disminución permanente de la integridad física o cuando de alguna manera sean contrarios al orden público o a las buenas costumbres. Empero, son válidos si su exigencia corresponde a un estado de necesidad, de orden médico o quirúrgico o si están inspirados por motivos humanitarios.

Como se observa, el Código Civil consagra el derecho irrenunciable a la integridad física. Surgen en este punto tres temas que merecen algún nivel de desarrollo por su especial vinculación con nuestra materia:

a) La donación de órganos;

b) La esterilización, $\mathrm{y}$

c) El cambio de sexo

En la primer cuestión contamos en Perú y Venezuela, por ejemplo, con una legislación especial que recoge la tendencia generalizada en la materia que es la de facilitar la donación post mortem de cualquier clase de órgano (e incluso en vida) de aquellos órganos o tejidos que aun cuando no se regeneran, su extirpación no perjudica gravemente la salud del donante ni reduce sensiblemente su tiempo de vida.

Las disposiciones contenidas en los artículos 60., 7o. y 9o. que se refieren a la protección del cuerpo y a la cesión de órganos, tejidos o partes del organismo que no se regeneran constituyen una novedad en relación con el Código Civil de 1936.

La regla contenida en este artículo tiene como objetivo la protección del cuerpo, considerado como una unidad sicosomática, es decir de la llamada "integridad personal”. De ahí que la norma, en su primer párrafo, prohíbe los actos de disposición del propio cuerpo cuando ocasionan una disminución permanente del mismo o cuando de alguna manera son contrarios al orden público o a las buenas costumbres.

Sin embargo, y excepcionalmente, puede disponerse de órganos en los siguientes casos:

1. Cuando exista estado de necesidad médico o quirúrgico pues en este caso se trata de una especial medida tendente a proteger la salud y en última instancia la vida. 
2. Cuando el acto está orientado a fines humanitarios (donación de órganos, sangre, etcétera) siempre que no se perjudique la salud o reduzca el término de vida.

En ambos casos es indispensable (de acuerdo con el artículo 7o. del mismo Código Civil) que la disposición no disminuya el tiempo de vida del donante, que exista un consentimiento expreso y escrito del donante y por último que no se persiga un fin de lucro.

En conclusión, la regla establecida en el Código Civil sobre la materia es la autorización limitada para la disposición de los propios órganos y la prohibición de la disposición del derecho a la integridad personal.

Más arriba hemos visto que nuestro Tribunal Constitucional rechaza enérgicamente la esterilización como política oficial de control de población, cabe ahora preguntarse por la esterilización voluntaria, ya sea que esté motivada por razones terapéuticas o anticonceptivas.

En esta hipótesis entran en juego el derecho a la libertad de la persona para proyectar su vida pero también con el derecho de la sociedad en cuanto la esterilización tiene indudable repercusión sobre el destino de la especie humana.

En nuestro medio se tolera la esterilización voluntaria mientras que en otros ordenamientos se encuentra legalmente prevista aunque sujeta a especiales requisitos (tal es el caso de Noruega, Suecia, Panamá, Japón y algunos estados de la Unión Americana). ${ }^{28}$ Frente a los anteriores ordenamientos, los de España y Somalia (entre otros) prohíben expresamente la posibilidad de recurrir a la esterilización voluntaria incluyendo tal conducta en el título relativo al delito de lesiones.

La versión original del artículo VI del título preliminar del Decreto Legislativo 346, Ley de Política Nacional de Población de nuestro país, excluía taxativamente a la esterilización y al aborto como método de planificación familiar. Más tarde, la Ley 26530 del 9 de Septiembre de 1995

28 El derecho a la esterilización es concedido a personas que superen los 25 años de edad y negada a los mayores de entre 18 y 21 . Las personas entre los 21 y 24 años pueden optar por la esterilización voluntaria si su solicitud es aceptada y aprobada por una comisión. Tal aprobación es concedida por motivos de salud (comprendidos aquellos que pondrían a la pareja en la imposibilidad de ocuparse de los hijos), así como por razones genéticas o socioeconómicas. No se requiere el consentimiento del cónyuge o conviviente. 
modifica dicho artículo incluyendo a la esterilización como método de planificación familiar. ${ }^{29}$

El último tema que podría dar lugar a controversia es el del cambio de sexo. En el ámbito científico el debate sobre esta posibilidad no se ha cerrado ni mucho menos. Algunos autores sostienen la procedencia de este tipo de intervención quirúrgica ya que contribuye a resolver el problema de identidad sexual. Dicha operación, según sostienen estos autores, tiende a adecuar los caracteres sexuales externos al verdadero sentimiento de la persona, a sus inclinaciones sicológicas y a su habitual comportamiento social. ${ }^{30}$

29 Esa norma ha sido declarada inconstitucional mediante la sentencia cuyos considerandos reprodujéramos más arriba. Un amplio desarrollo de la cuestión puede verse en Espinoza Espinoza, Juan, Estudios de derechos de la persona, 2a. ed., Lima, Huallaga, 1996, pp. 150 y ss.

30 El Tribunal Constitucional no se ha pronunciado específicamente sobre el tema pero en el expediente 2868-2004-AA declaró fundada la demanda de amparo de un funcionario policial que contrajo matrimonio con una persona que originariamente era de su mismo sexo pero que por medios quirúrgicos decidió cambiarlo adulterando su documentación. En dicho caso se resolvió que: “A juicio del Tribunal Constitucional, el primer motivo de la sanción impuesta puede analizarse desde una doble perspectiva. En primer término, que tal sanción se impuso por casarse con una persona que habría 'previamente adulterado sus documentos personales'. O, en segundo término, que la sanción obedezca a haber mantenido 'relaciones sospechosas' con un transexual. Por lo que hace al primer motivo, es decir, que la sanción se justifique porque el acto matrimonial se haya realizado con un tercero, el cual, para llevarlo a cabo, haya cometido un delito, es lícito que el Tribunal se pregunte si es que en un Estado constitucional de derecho es válido que una persona sea sancionada por un acto ilícito cuya realización se imputa a un tercero (la respuesta negativa se impone).

"Cabe, no obstante, entender que la sanción impuesta no sólo haya obedecido a las razones que antes se han expuesto, sino también al hecho de haber mantenido relación de convivencia con un transexual, con "anomalías físicas" en sus órganos genitales, pese a conocer tal condición, o tener que razonablemente haberlo inferido dada su condición de auxiliar de enfermería.

"A criterio del Tribunal, tal cuestión pone de manifiesto un doble orden de problemas. Por un lado, si la convivencia con un transexual puede o no ser considerada ilícita desde el punto de vista del derecho administrativo sancionador, y, por otro, vistas las razones expuestas en la parte considerativa de la Resolución Regional, en virtud de la cual se sanciona al recurrente, la coherencia interna del acto administrativo sancionador.

"Respecto al primer asunto, el Tribunal debe destacar que, de conformidad con el artículo 1o. de la Constitución, la defensa de la persona humana y el respeto de su dignidad son el fin supremo de la sociedad y del Estado. En ese sentido, el respeto por la per- 
Frente a lo anterior, otra importante corriente asevera que lo decisivo no es facilitar una supuesta adecuación al otro sexo, sino adoptar las medidas preventivas o de rehabilitación en orden a la afirmación y vivencia del sexo de origen, ya que la tendencia al cambio de sexo constituye un problema sicológico que debe ser tratado médicamente.

A contrario sensu debe entenderse, por supuesto, que no cabe considerar como lesión del derecho a la integridad física la intervención quirúrgica que tienda a la confirmación del sexo de origen. ${ }^{31}$

\section{EL CASO PARTICULAR DE LAS PERSONAS PRIVADAS DE LIBERTAD}

Para comenzar diremos que, con sustento en la jurisprudencia nacional y comparada, existe entre los internos de las unidades penitenciarias y la administración pública una especial relación de sujeción que permite avanzar sobre los derechos de los individuos en niveles que exceden largamente la medida de la potestad estatal respecto del resto de los ciudadanos.

Una de las finalidades que persiguen las instituciones penitenciarias es la retención y custodia de los internos

lo que se traduce en el deber de las autoridades penitenciarias de organizar los adecuados sistemas de vigilancia y seguridad en los establecimientos al objeto de garantizar aquella finalidad; de ahí que el Reglamento Penitenciario mencione entre los criterios organizativos del establecimiento penitenciario un sistema integral que garantice la custodia de los internos. ${ }^{32}$

sona se convierte en el leit motiv que debe informar toda actuación estatal. Para tales efectos, la Constitución peruana no distingue a las personas por su opción y preferencias sexuales; tampoco en función del sexo que pudieran tener. Se respeta la dignidad de la persona...

"Considerando ilegítima la opción y determinada preferencia sexual de una persona, con la consecuencia de sancionarla administrativamente, si es un servidor público, simultáneamente el Estado, de modo subrepticio, está imponiendo como jurídicamente obligatorio lo que él, autoritariamente, o una mayoría, juzga como moralmente bueno".

31 Un amplio desarrollo sobre estas cuestiones puede encontrarse en Fernández Sessarego, Carlos, Derecho de las personas, Lima, Studium, 1986, pp. 43 y ss.

32 Sentencia T-317/97 emitida por la Corte Constitucional de Colombia del 25 de junio de 1997. En la misma se ha resuelto también que "siguiendo los criterios constitucio- 
Naturalmente que las restricciones impuestas no alcanzan el derecho a la integridad corporal. Al respecto, nuestro Tribunal Constitucional tiene resuelto que:

el traslado de los internos de un establecimiento penal a otro, no es en sí mismo un acto inconstitucional. En efecto, tratándose de personas privadas legalmente de su libertad locomotora, una obligación de la que no pueden rehuir las autoridades penitenciarias es la de prestar las debidas garantías para que no se afecte o lesione la vida, la integridad física y los demás derechos constitucionales que no hayan sido restringidos. Ello supone que, dentro de márgenes sujetos al principio de razonabilidad, las autoridades penitenciarias no sólo puedan, sino que deban adoptar aquellas medidas estrictamente necesarias para preservar los derechos constitucionales de los internos, cada vez que existan elementos razonables que adviertan sobre el eventual peligro en el que éstas se puedan encontrar.

Como puede apreciarse, el traslado de un detenido desde un centro penitenciario a otro distinto puede ser dispuesto por la autoridad penitenciaria jugando el derecho a la integridad personal un doble papel, ya que por un lado puede justificar el cambio como sucede cuando en un establecimiento no se puede garantizar la integridad de un interno mientras que por otro lado es un límite, pues el traslado no puede perjudicar la integridad física del detenido.

En el primer sentido nuestro Tribunal Constitucional ha resuelto que "si el motivo que impulsó el traslado del beneficiario del habeas corpus, fue evitar que se lesionen la vida y su integridad, lo congruente es que la administración penitenciaria tenga que prever y ejecutar aquellas medidas necesarias que garanticen los bienes jurídicos que se pretenden proteger". 33

nales y legales sobre la organización del Estado, debe entenderse que al sistema penitenciario y carcelario le corresponde el cumplimiento de las medidas de aseguramiento, de la ejecución de las penas privativas de la libertad personal y de las medidas de seguridad. Ello explica que, necesariamente, los centros de reclusión estén organizados bajo un régimen restrictivo, y que la conducta de los internos se encuentre bajo vigilancia y control permanentes, buscando garantizar con ellos el orden, la disciplina, y un mínimo de condiciones de moralidad, seguridad y salubridad; todo ello, en aras de cumplir las funciones retributiva, protectora, preventiva y resocializadora que el ordenamiento jurídico le ha atribuido a la pena".

33 Considerando 5 de la sentencia recaía en el expediente 0726-2002-HC/TC. 
En el segundo sentido el máximo intérprete de la Constitución tiene resuelto que si "no se demostró que el cambio de ambiente haya hecho peligrar la integridad física del actor, que se encuentra interno en el establecimiento penal de Moyobamba, éste resulta perfectamente válido". ${ }^{34}$

Pese a la naturaleza reseñada de las relaciones jurídicas que se establecen entre la administración penitenciaria y los internos de los establecimientos, éstos conservan todos los derechos reconocidos a los ciudadanos por las normas de nuestro ordenamiento, con excepción, obviamente, de aquellos que son incompatibles con el objeto de la detención o el cumplimiento de la condena; y también que las actuaciones penitenciarias deberán llevarse a cabo respetando, en todo caso, la personalidad humana de los recluidos y los derechos e intereses de los mismos no afectados por la condena. Entre los que la legislación en esta materia expresamente garantiza se encuentra el de la integridad personal de los internos.

Al respecto el Tribunal Constitucional ha resuelto que:

siendo la vida y la integridad física derechos fundamentales de la persona, consagrados como de categoría constitucional en nuestra carta magna, y atendiendo a que el objeto de esta controversia busca cautelar su aplicación a favor del afectado, este Tribunal ha verificado la debida atención médica, de conformidad con lo preceptuado en los artículos 76o. al 82o. del Código de Ejecución Penal. ${ }^{35}$

Las actividades regimentales que se desarrollan en los establecimientos penitenciarios para garantizar la vigilancia y seguridad interior, alcanzan también el "Registro y control de las personas (provenientes del exterior) autorizadas a comunicarse con los internos...".

Queda claro entonces que constituye un deber para las autoridades penitenciarias combatir la posesión de elementos prohibidos o peligrosos como drogas, armas, explosivos, etcétera,

obedeciendo su explicitación normativa, muy plausible, por otra parte, a una consolidada tendencia internacional a plasmar medida tan frecuente, pero no por ello menos atentatoria, potencialmente, a los derechos fundamentales de los reclusos, en los textos normativos de referencia, llegando alguno de ellos, como la ley penitenciaria alemana, a autorizar el registro corporal desnudan- 
do a los internos en lugar cerrado en supuestos de peligro grave o por orden del director del centro. ${ }^{36}$

Este es el criterio que adopta el Tribunal Constitucional Español en la sentencia 57/94 donde se resolvió que:

la orden impartida al recluso ${ }^{37}$ no se considera que, ni por su finalidad ni por su mismo contenido o por los medios utilizados hubiera podido acarrear un sufrimiento de especial intensidad o provocar una humillación o envilecimiento al sujeto pasivo, no constituyendo, por lo tanto, un trato vejatorio y degradante, prohibido por el artículo 15 de la Constitución Española.

Es indudable que una medida de registro personal de los reclusos puede constituir, en determinadas situaciones, un medio necesario para la protección de la seguridad y el orden de un establecimiento penitenciario. Y entre tales situaciones se halla ciertamente, aquella en la que existe una situación excepcional en el centro, con graves amenazas de su orden interno y su seguridad por el comportamiento de los reclusos, como se ha reconocido por la Comisión Europea de Derechos Humanos (Decisión de 15 de mayo de 1990, caso McFeel y otros) al declarar proporcionada a la finalidad perseguida una medida de registro similar a la evaluada en la sentencia 57/94 ya citada.

Corresponde señalar que en el caso el máximo tribunal dispuso que por las particularidades del caso se había violado efectivamente el derecho a la intimidad del detenido. En tal sentido se resolvió que su ámbito de intimidad

...se vio innecesariamente restringido más allá de lo que la ordenada vida de la prisión requiere, afectando a su dignidad personal... [sin embargo] las medidas de control, aun cuando restrinjan la intimidad corporal de los internos, pueden ser constitucionalmente legítimas si están justificadas por su finalidad, se fundamentan en las circunstancias del centro penitenciario y, además, por los medios utilizados para su práctica no se produce una afectación de los derechos fundamentales.

36 Gil Hernández, Ángel, Intervenciones corporales y derechos fundamentales, Madrid, Colex, 1995, p. 79.

37 Consistente en desnudarse y hacer flexiones luego de una visita con contacto personal y ante la sospecha de que portaba droga en sus cavidades naturales. 
Es decir que, en la doctrina del Tribunal Constitucional español, este tipo de control aplicado a un interno no implica una afectación del derecho a la integridad física, ni constituye, si se ejecuta en las condiciones reseñadas, un trato inhumano o degradante.

Por su parte, la Jurisprudencia de la Corte Suprema de los Estados Unidos en la misma materia se muestra oscilante ya que en autos Hudson contra Palmer sostuvo que "los reclusos no gozan de expectativas razonables de protección de su intimidad", mientras que con un criterio opuesto ha interpretado que en virtud de la Decimocuarta Enmienda, la Cuarta Enmienda se aplica en los 50 estados y constituye un criterio mínimo que debe cumplir la legislación de cada estado. Además, las Constituciones de aproximadamente dos terceras partes de los estados establecen prohibiciones de registro e incautación esencialmente iguales. De hecho, la Cuarta Enmienda de la Constitución de los Estados Unidos se inspiró en el artículo 14 de la Constitución de Massachusetts de 1780. En algunos estados, la protección constitucional del derecho "a la intimidad" puede cumplir la misma función que la Cuarta Enmienda o incluso brindar mayor protección (véase, por ejemplo, el artículo 1o., § 22 de la Constitución de Alaska, el artículo 1o., $\$ 13$ de la Constitución de California y el artículo 2o., $\$ 10$ de la Constitución de Montana).

Cualquier medida tendente a garantizar el objetivo colectivo de seguridad y que restrinja en alguna medida los derechos fundamentales de las personas privadas de libertad, debe reunir una serie de requisitos que fueron delineados por la Comisión Interamericana de Derechos Humanos en el caso de la Señora X y su hija menor Y contra el Estado argentino.

El Tribunal Constitucional del Perú tiene resuelto que cualquier acto

que, al margen de su intencionalidad, incida o repercuta en esferas subjetivas o derechos que no están restringidos, afecta el derecho y principio a la dignidad. La condición digna es consustancial a toda persona y el hecho de que esté restringido el derecho a la libertad como consecuencia de una sanción penal, por más abominable y execrable que haya sido el hecho que motivara su aplicación, nunca enervará o derogará el núcleo fundamental de la persona, su dignidad. ${ }^{38}$

38 Considerando 5 de la sentencia recaía en el expediente 1429-2002-HC/TC. Con cita de la anterior y adoptando idéntico criterio se ha emitido sentencia en el expediente 797-2002-HC-TC del 20 de noviembre del 2002. 
La jurisprudencia de la Corte Constitucional de Colombia entendió en su primera época que la dignidad era un principio constitucional vinculante de valor absoluto, que no admitía limitación bajo ninguna circunstancia, ni aún en el caso de detenidos: "es el presupuesto esencial de la consagración y efectividad del entero sistema de derechos y garantías contemplado en la Constitución" (sentencias T-499/92 y T-522/92), "La dignidad del ser humano constituye razón de ser, principio y fin último de la organización estatal" (T401/92). En una segunda etapa, la jurisprudencia asumió la dignidad no sólo como un principio sino también como un derecho fundamental autónomo, "de eficacia directa" y susceptible de ser amparado a través de acciones de tutela. En cuanto a la restricción de otros derechos, la misma Corte ha resuelto que la persona detenida "a pesar de tener suspendido su derecho a la libertad física, aún es titular y ejerce sus otros derechos fundamentales, los cuales sólo pueden ser restringidos en menor o mayor magnitud debido a su nexo con la reclusión, pero permanecen intactos en su núcleo esencial". ${ }^{39}$

Las condiciones para autorizar restricciones adicionales a los derechos de las personas detenidas que vienen delineados, como se dijera en el informe 38/96 de la Comisión Interamericana de Derechos Humanos son las siguientes:

1. Ser prescritas por la ley. El principio de legalidad es ineludible que sea colocado en el primer lugar ya que nadie está obligado a hacer lo que la ley no manda ni privado de lo que ella no prohíbe.

2. Ser necesarias para mantener la seguridad común. Es decir, que se requiere que la medida venga impuesta por una necesidad objetiva intentando cerrar las puertas a la arbitrariedad.

3. Ser razonables guardando relación con los objetivos y las exigencias propias del Estado de derecho. Nuestro Tribunal Constitucional tiene resuelto sobre el particular que "cualquier restricción de algún derecho constitucional o de cualquier esfera subjetiva del interno, tendrá condicionada su validez constitucional a la observancia del principio de razonabilidad". ${ }^{40}$

Adicionalmente ha sostenido que

40 Considerando 3 de la sentencia recaída en el expediente 1429-2002-HC/TC. 
Tratándose de personas privadas legalmente de su libertad locomotiva, una obligación de la que no pueden rehuir las autoridades penitenciarias es la de prestar las debidas garantías para que no se afecte o lesione la vida, la integridad física y los demás derechos constitucionales que no se les haya restringido. Ello supone que, dentro de márgenes sujetos al principio de razonabilidad, no sólo puedan sino que deban adoptarse aquellas medidas estrictamente necesarias con el objeto de preservarlas. ${ }^{41}$

4. Que su aplicación resulte proporcional. Si se cumplen los requisitos anteriores, el de la proporcionalidad viene a constituirse en el eje definidor de lo permisible. Al respecto, en el informe de la CIDH citado se sostiene que "La restricción a los derechos debe ser proporcional al interés que la justifica y ajustarse estrechamente a ese objetivo", balanceando el interés de familiares y detenidos de realizar visitas sin restricciones arbitrarias frente al interés público de garantizar la seguridad en las penitenciarías (considerando 70).

Claro está que lo expresado se refiere a la persona detenida pero una medida de similar naturaleza no puede aplicarse por analogía a personas que no se encuentran afectadas por esa especial relación de sujeción aunque tomen contacto directo con los detenidos.

Queda claro que existen derechos que no pueden ser afectados en lo más mínimo, como el derecho a la vida o el relativo a la dignidad de la persona humana y consecuente con esta idea la normativa penitenciaria debe establecer con claridad que el trato que se brinde a las personas que pretendan una visita con contacto personal debe ser humanitario, así como que la requisa debe ser practicada respetando los derechos de la persona.

El considerando 99 del mencionado Informe 38/96 de la Comisión Interamericana de Derechos Humanos dispone que "Las visitas con contacto personal no son un derecho y en muchos países este tipo de visita ni siquiera es una opción. Generalmente la posibilidad de visitas de contacto personal queda librada a la discreción de las autoridades de la penitenciaría".

Efectivamente este tipo de visitas de los internos no constituye un derecho, pero una vez que se encuentra autorizado por el ordenamiento

41 Considerando 4 de la sentencia recaída en el expediente 0622-2002-HC/TC. 
debe reconocerse que ha surgido a favor de los individuos la potestad de exigir su cumplimiento y por lo tanto cualquier restricción debe ajustarse a las cuatro condiciones ya expuestas.

La Corte Interamericana de Derechos Humanos, en autos Velásquez Rodríguez, sostiene que existen "ciertos atributos inviolables de la persona humana" que están más allá de la esfera de acción del Estado y que no pueden ser legítimamente menoscabados por el ejercicio del poder público". 42

Frente a lo anterior, el inciso 2o. del artículo 32 de la Convención Americana sobre Derechos Humanos dispone que "Los derechos de cada persona están limitados por los derechos de los demás, por la seguridad de todos, y por las justas exigencias del bien común, en una sociedad democrática".

Queda claro, además que, de acuerdo con el artículo 29 de la Convención ninguna disposición puede ser interpretada en el sentido de "Permitir a alguno de los Estados... suprimir el goce y ejercicio de los derechos y libertades reconocidos en la Convención o limitarlos en mayor medida que la prevista en ella".

Por lo tanto, queda claro que existen derechos que no pueden ser afectados en lo más mínimo como el derecho a la vida o el relativo a la dignidad de la persona humana y en consecuencia la normativa penitenciaria debe establecer con claridad que el trato que se brinde a las personas que pretenden una visita con contacto personal, así como la requisa que resultare del caso deben ser humanitarias.

Tratándose de visitas con contacto personal, el mantenimiento de la seguridad autoriza tomar especiales medidas de precaución que vienen impuestas por la creatividad de los individuos que se prestan a introducir objetos prohibidos como teléfonos celulares, armas, explosivos, drogas, etcétera.

Al respecto, se ha resuelto que la verificación de la prueba de un registro personal supone para el afectado "un sometimiento no ilegítimo desde la perspectiva constitucional a las normas de policía, sometimiento al que incluso puede verse obligado sin la previa existencia de indicios de infracción, ${ }^{43}$ en el curso de controles preventivos realizados por los encargados de velar por la seguridad" (sentencias del Tribunal Constitu-

43 Nótese que basta con la simple sospecha como categoría inferior al indicio. 
cional Español del 15 de abril de 1993 y concordantes como las del 20 de noviembre del 1993 y 20 de diciembre de 1993).

Por lo expuesto concluimos que se pueden limitar los derechos a la intimidad e integridad corporal en cumplimiento del deber de seguridad inherente a la función del servicio penitenciario y atendiendo al fin retributivo, protector, preventivo y resocializador que el ordenamiento jurídico le ha atribuido a la pena, ${ }^{44}$ pero siempre dentro de una medida que no afecte el núcleo esencial de los derechos involucrados.

\section{CONCLUSIÓN}

El derecho a la integridad personal tiene reconocimiento expreso en el texto de la Constitución Política del Perú, y adicionalmente el Tribunal Constitucional lo reconoce entre los derechos fundamentales inherentes a la persona humana.

Posee una doble vertiente ya que se protege la integridad física pero también el aspecto sicológico y moral de la persona.

La libertad de contratación, el derecho de asociación, el derecho de ejercer toda industria lícita, el derecho de comerciar, la finalidad legítima de preservar el vínculo matrimonial y el impedimento constitucional de la prisión por deudas son algunos de los derechos que pueden verse limitados en función de la preferencia del derecho a la integridad personal expresamente analizados en el ámbito peruano.

La normativa penal prevé una serie de figuras delictivas que afectan el derecho a la integridad personal para el caso que la afectación sea cometida por particulares, pero también se encuentran vedados la tortura y los tratos o penas crueles, inhumanos o degradantes cuando la conducta deba ser imputada a agentes estatales.

Cuando existan actos u omisiones que importen violación o amenaza de derechos diferentes de la libertad personal, pero cuya eventual lesión se genera, precisamente, como consecuencia directa de una situación de

44 En los "Principios básicos para el tratamiento de los reclusos" se establece que: “4. El personal encargado de las cárceles cumplirá con sus obligaciones en cuanto a la custodia de los reclusos y la protección de la sociedad contra el delito de conformidad con los demás objetivos sociales del Estado y con su responsabilidad fundamental de promover el bienestar y el desarrollo de todos los miembros de la sociedad", Asamblea General, Resolución 45/111, Annex, 45 U.N. GAOR Supp. (núm. 49A) p. 200, ONU Doc. A/45/ 49 (1990). 
privación o restricción del derecho a la libertad individual se puede recurrir a la garantía Constitucional del habeas corpus.

El Código Civil también se ocupa del tema estableciendo una prohibición general en cuanto a la posibilidad de disponer del derecho a la integridad personal y una autorización limitada para la disposición de los propios órganos (cuando exista estado de necesidad médico o quirúrgico o cuando el acto está orientado a fines humanitarios, siempre que no se perjudique la salud o reduzca el término de vida).

Las personas privadas de libertad conservan todos los derechos reconocidos a los ciudadanos por las normativa salvo por supuesto aquellos incompatibles con el cumplimiento de la condena. Naturalmente que las restricciones que puedan imponérsele no alcanzan el derecho a la integridad corporal.

El registro corporal que se practique a aquellas personas no se encuentra vedado pero su constitucionalidad depende de que estén justificados por su finalidad, se fundamentan en las circunstancias del centro penitenciario y que los medios empleados no afecten los derechos fundamentales.

Por último, coincidimos con la doctrina del Tribunal Constitucional español en cuanto sostiene que las inspecciones en alguna medida invasivas practicadas a las personas que pretendan acceder a una visita con contacto personal, no constituyen un sometimiento ilegítimo pero siempre que se practiquen respetando las condiciones que se describen en el Informe 38/96 de la Comisión Interamericana de Derechos Humanos. 